\title{
EFEITOS DA SHANTALA NA INTERAÇÃO ENTRE MÃE E CRIANÇA COM SÍNDROME DE DOWN
}

\author{
EFFECTS OF SHANTALA MASSAGE THERAPY ON \\ INTERACTION BETWEEN MOTHER AND CHILD \\ WITH DOWN'S SYNDROME
}

\author{
Karina Crepaldi Barbosa ${ }^{1}$ \\ Simone Nomie Sato ${ }^{1}$ \\ Elaine Gomes dos Reis Alves ${ }^{2}$ \\ Alexandre Luiz Affonso Fonseca ${ }^{3}$ \\ Fernando Luiz Affonso Fonseca ${ }^{4}$ \\ Virgínia Berlanga Campos Junqueira ${ }^{4}$ \\ Alessandra Marques ${ }^{5}$ \\ Tatiana Dias de Carvalho ${ }^{6}$ \\ Ligia Ajaime Azzalis ${ }^{7}$
}

Barbosa $\mathrm{KC}$ et al. Efeitos da Shantala na interação entre mãe e criança com síndrome de down. Rev Bras Cresc e Desenv Hum 2011; 21(2): 369-374.

\section{RESUMO}

O objetivo é verificar os efeitos da Shantala na interação entre mãe e criança com síndrome de Down. Utilizou-se por 60 dias, uma vez por semana, a técnica de massagem Shantala em três crianças com síndrome de Down, da instituição APAE, localizada em Itaquaquecetuba, SP, Brasil. Para a obtenção dos resultados foram aplicados dois questionários, um ao início, para se obter maiores informações sobre as crianças e outro ao final, para se verificar os resultados da técnica utilizada. Foi possível concluir que a Shantala beneficiou as crianças com síndrome de Down, proporcionando uma qualidade de vida melhor. Para as mães, a técnica permitiu uma melhor aceitação da doença e houve melhora no relacionamento entre as mães e as crianças.

Palavras-chave: síndrome de down, shantala, criança.

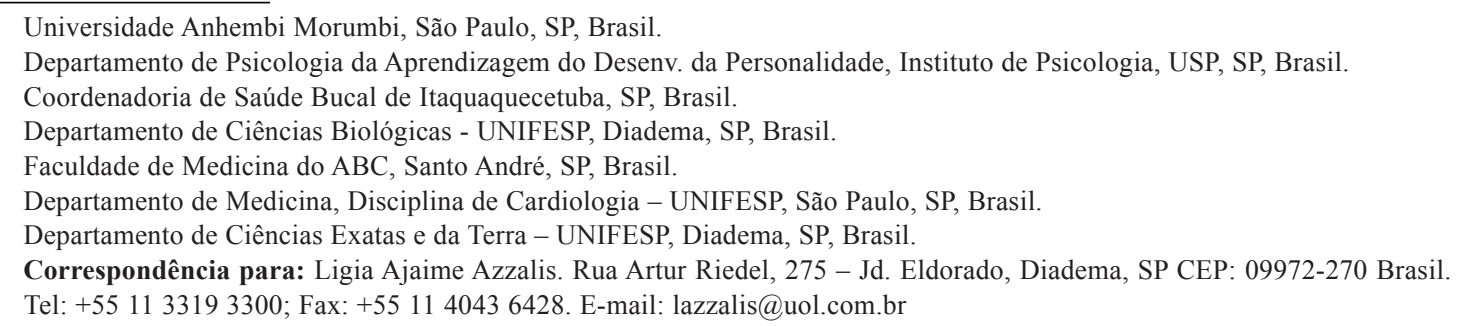




\begin{abstract}
This study aimed to verify the effects of Shantala massage therapy on the interaction between mother and child with Down's syndrome. The methodology consisted in applying the massage technique "Shantala" for 60 days, once a week, on three children from APAE Institution, located at Itaquaquecetuba, SP, Brazil. At the beginning of the treatment we applied a questionnaire to obtain more information about the patient. At the end, it was applied another questionnaire to verify the results of the treatment. It was observed that Shantala benefited the kids with Down's syndrome, providing to them a better quality of life. For the mothers, the technique provided a better acceptability of the disease and an improvement in the relationship between mothers and kids.
\end{abstract}

Key words: down's syndrome, shantala, child.

\section{INTRODUÇÃO}

A síndrome de Down (SD) tem registros antigos na história do homem, sendo os primeiros trabalhos científicos datados do século XIX. Entretanto, seu reconhecimento como uma manifestação clínica só ocorreu com o trabalho de Langdon Down, em 1866 $6^{1,2}$.

Cerca de $95 \%$ de todos os pacientes com SD possuem trissomia do cromossomo 21 , resultado da não-disjunção meiótica do par de cromossomo $21^{2,3}$. Esta síndrome pode ser diagnosticada logo após o nascimento devido à manifestação dos seus principais fenótipos, como: hipotonia muscular generalizada, occipital achatado, pescoço curto e grosso, prega única na palma das mãos e alteração no comprimento $^{4,5}$.

Crianças com Síndrome de Down seguem uma curva de desenvolvimento motor própria ${ }^{4}$. É muito importante receberem estímulos desde pequenas para desenvolverem interesses e habilidades que são necessários para a realização de atividades físicas e recreacionais ${ }^{4-6}$. A alegria e satisfação pelo uso efetivo do corpo contribuirão para tornar suas atividades mais agradáveis e recompensadoras ${ }^{7,8}$, além de promover a interação com o meio ${ }^{2}$.

Os lactentes com SD podem se engajar com menos frequência em atividades de inte- ração com o ambiente, seja por dificuldades em registrar estímulos cotidianos (como diferentes sons e pessoas), ou por dificuldades em explorar o meio utilizando habilidades moto$\mathrm{ras}^{8,9}$. As intervenções motoras permitem avanços nas áreas da motricidade global, equilíbrio e organização espacial, justificando a relevância de programas de intervenção para essa população ${ }^{9,10}$.

A massagem terapêutica tem demonstrado efeitos positivos no comportamento motor de diversas crianças ${ }^{6,11}$. A Shantala é uma massagem originária do sul da Índia e é transmitida oralmente de geração para geração. Foi descoberta por Frederick Leboyer ${ }^{11}$, médico francês que, em uma de suas viagens ao sul da Índia, pôde observar uma mãe massageando seu filho; e batizou a sequência de movimentos com o mesmo nome da mãe que a realizava: Shantala ${ }^{6}$.

São muitos os benefícios da técnica Shantala, a começar pelo aperfeiçoamento da comunicação com a mãe ou com quem estiver fazendo a massagem, pois o processo beneficia tanto a criança quanto quem está interagindo com ela. Deve-se praticar a massagem nos quatro primeiros meses de vida, ou enquanto a criança não consegue movimentarse. No entanto, quanto mais tempo a técnica for praticada, melhor será o seu benefício ${ }^{6}$. 
Este estudo objetiva avaliar os efeitos da técnica Shantala em crianças com síndrome de Down.

\section{MÉTODO}

O estudo é descritivo, de natureza qualitativa e foi desenvolvido na APAE Itaquaquecetuba, SP, Brasil. Após a aprovação do trabalho pelo Comitê de Ética em Pesquisa da Universidade Anhembi Morumbi (protocolo 012/2009), foram realizadas duas palestras explicativas, uma para os profissionais da instituição APAE e outra para os responsáveis das crianças.

Três crianças com síndrome de Down foram incluídas no estudo. Os critérios de inclusão foram: crianças com síndrome de Down, entre um e três anos de idade. Foram excluídas crianças com doenças degenerativas.

A intervenção terapêutica foi a utilização da Shantala, em sessões de 20 minutos, uma vez por semana, por 60 dias. Os pais e/ou cuidadores se comprometeram a aplicar a massagem diariamente, de acordo com as orientações recebidas, por pelo menos 15 minutos.
Foram aplicados dois questionários, um ao início, para se obter maiores informações sobre as crianças, e outro ao final, para verificar os resultados da técnica utilizada.

\section{RESULTADOS}

As respostas iniciais obtidas foram: as três crianças atendidas moram com os pais; apenas uma criança possui irmãos (duas irmãs adolescentes); todas as crianças ficam a maior parte do dia com a mãe, em casa; apenas uma das mães conhecia a técnica Shantala; todas as mães costumam acariciar, embalar e conversar com as crianças diariamente, ao trocar a fralda ou durante o banho, por aproximadamente dez minutos.

Ao final do estudo, as respostas obtidas foram: as três crianças tiveram um sono mais tranquilo; uma delas conseguiu executar mais movimentos, como andar sem apoio; as outras duas aperfeiçoaram os movimentos que já realizavam anteriormente.

O quadro 1 apresenta os relatos das mães das crianças que participaram do estudo (criança 1 , criança 2 , criança 3 ), antes e após o tratamento.

Quadro 1: Características das crianças antes e após o tratamento

\begin{tabular}{|lll|}
\hline Voluntário & Antes do tratamento & Após o tratamento \\
\hline Criança 1 & $\begin{array}{l}\text { É uma criança agitada, inquieta, se } \\
\text { movimenta muito, mesmo estando no } \\
\text { colo das pessoas. Apresenta } \\
\text { dificuldade para dormir. }\end{array}$ & $\begin{array}{l}\text { A criança ficou mais calma, bem } \\
\text { menos agitada, sem dificuldades } \\
\text { para dormir e muito "serena" ao } \\
\text { acordar. }\end{array}$ \\
\hline Criança 2 & $\begin{array}{l}\text { A criança é bem agitada, brinca muito } \\
\text { com a mãe, irmãs e pai, porém não } \\
\text { se relaciona facilmente com outras } \\
\text { pessoas. }\end{array}$ & $\begin{array}{l}\text { A criança ficou mais tranquila. } \\
\text { Dormia melhor e ao acordar, se } \\
\text { encontrava mais disposta para } \\
\text { brincar. }\end{array}$ \\
\hline Criança 3 & $\begin{array}{l}\text { A criança é agitada e inquieta. Recebe } \\
\text { da mãe brincadeiras e massagens ao } \\
\text { trocar a fralda. A mãe relata que a } \\
\text { criança fica mais calma e aparenta } \\
\text { gostar. }\end{array}$ & $\begin{array}{l}\text { A criança teve um sono mais } \\
\text { tranquilo, ficando mais calma e } \\
\text { menos inquieta durante o dia. A } \\
\text { criança sentia mais segurança } \\
\text { para ficar em pé e, após o final } \\
\text { do tratamento, a criança } \\
\text { começou a andar sem apoio. }\end{array}$ \\
& &
\end{tabular}




\section{DISCUSSÃO}

O presente estudo descritivo, de natureza qualitativa, verificou os efeitos da Shantala em crianças de um a três anos de idade com síndrome de Down. Após 60 dias de aplicação dessa técnica, as três participantes tiveram um sono mais tranquilo e aperfeiçoaram seus movimentos.

Segundo a OMS, os procedimentos de intervenção para o desenvolvimento das crianças com SD são muito importantes porque proporcionam interação entre criança e o meio, juntamente com processos de superação e adaptação $0^{4,6,9,10}$.

O diagnóstico de síndrome de Down gera impacto nas mães. Em decorrência disso, elas apresentam dificuldade de construir expectativas em relação ao desenvolvimento e à escolarização de seus filhos ${ }^{12}$. Sabe-se que muitas famílias de portadores de necessidades especiais se retiram do convívio entre as demais pessoas da comunidade por vergonha ou preconceito $^{7,12,13}$. Fortalecer a interação cuidador e criança com necessidades especiais poderia contribuir para aumentar a aceitação da criança entre seus familiares e a própria comunidade.

Essas crianças requerem da família maior tempo e dedicação, especialmente se estiverem em fase de crescimento, período em que estímulos, atenção e cuidado são fundamentais ${ }^{13,14}$. Cabe ressaltar ainda que as interações estabelecidas na família são as que trazem implicações mais significativas para o desenvolvimento da criança ${ }^{14}$. A massagem, técnica comum no Oriente, favorece esse vínculo ${ }^{6,11}$.

No Brasil, a massagem mais utilizada é a Shantala ${ }^{6,11}$. Segundo Leboyer, o método se baseia no restabelecimento do equilíbrio de energias mediante o tato; estimula o desenvolvimento psicomotor da criança, além de favorecer seu relacionamento com a família, contribuindo para um melhor entendimento da síndrome ${ }^{15}$.
A Shantala, enquanto toque terapêutico, proporciona a estimulação cutânea e o desenvolvimento psicomotor. $\mathrm{O}$ toque estimula a pele, que, por sua vez, produz enzimas necessárias à síntese protéica. Ocorre também a produção de substâncias que ativam a diferenciação de linfócitos $\mathrm{T}$, responsáveis pela imunidade celular ${ }^{16}$.

Também são observadas diminuição dos níveis de catecolaminas ${ }^{16,17}$ e produção ativa de neurotransmissores responsáveis pelas sensações de alegria e de bem estar. Como consequência, a criança relaxa, o sono fica mais calmo e mais resistente a barulhos externos, a amamentação é facilitada, a ocorrência de cólicas diminui e o vínculo mãe e filho é ampliado ${ }^{16}$.

Em lactentes, a aplicação dessa massagem está associada ao ganho de peso e melhora do comportamento. Fogaça et al ${ }^{17}$ observaram diminuição nos níveis de cortisol salivar em crianças de quatro a seis meses após a massagem Shantala. A diminuição nos níveis de cortisol poderia indicar que ficaram menos estressadas após a massagem. De fato, no presente estudo, as crianças apresentaram um sono mais tranquilo, sentiram-se mais dispostas para brincar durante o dia, executando movimentos melhores do que realizavam antes do tratamento.

Apesar de descrita em 1866, pouco se conhece sobre a relação entre cuidador e criança com síndrome de Down, principalmente quanto à contribuição do cuidador no desenvolvimento motor da criança. A aplicação da massagem promove o toque e carinho, estreitando o vínculo entre mãe e fillho, contribuindo o desaparecimento de desconfortos comuns nos lactentes, como: cólicas e sono intranquilo ${ }^{16,18}$.

Em criança com SD, Carvalho e colaboradores ${ }^{19}$ verificaram melhora no tônus dos membros superiores, do controle cervical e na qualidade do sono. A aplicação da massagem Shantala resultou em melhora refletida pelo aumento de $36 \%$ para $60 \%$ de itens avaliados 
com padrão motor normal presente. A análise tanto dos resultados quanto do relato da mãe demonstra que a massagem Shantala contribuiu de forma positiva para o comportamento motor da criança estudada ${ }^{19}$.

Os resultados positivos da estimulação através da Shantala foram observados pela evolução em vários aspectos do comportamento motor, como desenvolvimento da linguagem, melhora da preensão manual e da transferência manual de objetos, melhora do controle cefálico, de tronco e de apoio para marcha, assim como da qualidade do sono ${ }^{19}$.

Ainda sobre os resultados da aplicação de massagem em crianças, Cruz e Caromano ${ }^{20}$ verificaram que a manipulação aumenta a saturação de oxigênio e com o decorrer do tempo, facilita o ganho de peso em crianças internadas em unidades de terapia intensiva. Uma

\section{REFERÊNCIAS}

1. Pereira-Silva NLP, Dessen MA. Síndrome de Down: etiologia, caracterização e impacto na família. Interação em Psicologia 2002; 6 (2): 167-176.

2. Moreira Lília MA, El-Hani CN, Gusmão FAF. A síndrome de Down e sua patogênese: considerações sobre o determinismo genético. Rev. Bras. Psiquiatr. 2000; 22 (2): 96-9.

3. Nussbaum RL, McInnes RR, Willard HF. Thompson \& Thompson Genética Médica. 7a. Ed. Rio de Janeiro: Elsevier, 2007.

4. Godzicki B, Silva PA, Blume LB. Aquisição do sentar independente na Síndrome de Down utilizando o balanço. Fisioter. Mov. 2010; 23 (1): 73-81.

5. Santos JA, Franceschini SCC, Priore SE. Curvas de crescimento para crianças com Síndrome de Down. Rev. Bras. Nutr. Clin. 2006; 21 (2): 144-148. massagem suave e firme, por 15 minutos, três vezes ao dia, em prematuros, resulta em ganho de peso, provavelmente em razão de um nível mais elevado de hormônios gastrintestinais; em melhor desempenho em testes de controle motor e de envolvimento com as pessoas, além de diminuição no tempo de internação ${ }^{20}$.

Neste trabalho foi possível verificar que a técnica Shantala fortaleceu o laço da mãe com a criança com SD, havendo um carinho maior, um contato mais afetivo e um melhor desenvolvimento psicomotor e, fundamentalmente um maior envolvimento do responsável com a criança, o que fortalece o vínculo parental. Assim, são necessários mais estudos com o mesmo objetivo, por se tratar de recurso de baixo custo e efetivamente positivo, tanto para o desempenho motor quanto para a interação entre mãe e filho.

6. Lima P. Estudo exploratório sobre os benefícios da Shantala em bebês portadores de síndrome de Down. Curitiba, junho 2004. Disponível em: < http:// dspace.c3sl.ufpr.br/dspace/bitstream/ 1884/2270/1/Mestrado-defesa.pdf. Acesso em: 2/11/2009.

7. Saraiva APVP, Nóbrega MS. Avaliação da Qualidade de Vida em pacientes com síndrome de Down na APAE- João PessoaParaíba. Pesq. Bras. Odontoped. Clin. Integr. 2003; 3 (2): 59-64.

8. Pueschel S et.al. Síndrome de Down - Guia para pais e educadores. $2^{\mathrm{a}}$. Ed. Campinas: PAPIRUS; 1997.

9. Campos AC, Coelho MC, Rocha, NACF. Desempenho motor e sensorial de lactentes com e sem Síndrome de Down: estudo piloto. Fisioter. Pesq. 2010;17(3): 203-208.

10. Santos APM, Weiss SLI, Almeida GMF. Avaliação e intervenção no desenvolvimento motor de uma criança com Síndro- 
me de Down. Rev. bras. educ. espec 2010;16(1): 19-30.

11. Leboyer F. Shantala: Massagem para bebês. 7. ed. São Paulo: Ground; 1998.

12. Lipp LK, Martini FO, Oliveira-Menegotto LM. Desenvolvimento, escolarização e Síndrome de Down: expectativas maternas. Paidéia (Ribeiräo Preto) 2010; 20(47): 371-379.

13. Sunelaitis RC, Arruda DC, Marcom SS. A repercussão de um diagnóstico de síndrome de Down no cotidiano familiar: perspectiva da mãe. Acta Paul. Enferm. 2007; 20 (3): 264-271.

14. Pereira-Silva NL, Dessen MA. Padrões de interação genitores-crianças com e sem síndrome de Down. Psicologia: Reflexão e Crítica 2006; 19 (2): 283-291.

15. Pinto E. Experiência Del masaje infantil en bebés con síndrome de Down. Sevilla, março 2009. Disponível em: <http:// www.Downcantabria.com/revistapdf/100/ 9-15.pdf. Acesso em: 02/11/2009.

16. Victor JF, Moreira TMM. Integrando a família no cuidado de seus bebês: ensinando a aplicação da massagem Shantala. Acta Scientiarum. Health Sciences 2004; 26(1):35-39.
17. Fogaça MC, Carvalho WB, Peres CA, Lara MI, Hayashi LF, Verreschi ITN. Salivary cortisol as an indicator of adrenocortical function in healthy infants, using massage therapy. Sao Paulo Med. J. 2005; 123 (5): 215-218.

18. Victor JF, Moreira TMM, BarrosoLMM. Shantala, Massagem Indiana para Bebês: um relato de experiência utilizando oficinas com mães primíparas. Nursing 2004: 75(7).

19. Carvalho RL, Moreira TM, Pereira MAG. Shantala no Desenvolvimento Neuropsicomotor em Portador da Síndrome de Down. Pensamento Plural: Revista Científica do UNIFAE 2010; 4(1):62-66.

20. Cruz CMV, Caromano FA. Characteristics of the massage techniques for babies. Rev. Ter. Ocup. Univ. São Paulo 2005; 16 (1): 47-53.
Recebido em: 08/ago./2010

Modificado em 26/nov./2010 Aceito em 16/mar./2011 